\title{
A Review of the Research on M\&A Behavior
}

\author{
Yan Wang ${ }^{\mathrm{a}}$, Shaoni Zhou ${ }^{\mathrm{b}^{*}}$, Yushan $\mathrm{Wu}^{\mathrm{c}}$, Sixiang $\mathrm{Wu}^{\mathrm{d}}$ \\ School of Economics and Management \\ Beijing Jiaotong University \\ Beijing, China \\ a pqwangy@126.com, b*2627095692@qq.com, ${ }^{\mathrm{c}}$ bjtubleven@163.com, ${ }^{\mathrm{d}} 17113164 @$ bjtu.edu.cn
}

\begin{abstract}
M\&A (mergers and acquisitions) have always been a hot topic. With the rapid development of the global economy and the intensified competition in recent years, M\&A have ushered in an unprecedented new situation both in terms of scale and transaction volume. Based on this, we have combed the literature research on $M \& A$, and based on behavioral economic theory, we have analyzed five kinds of same or similar companies M\&A behavior. After discussing each M\&A behavior, we have all carried out a summary, including the existing research results, deficiencies, and future research directions. Finally, we have summarized the existing research and put forward research proposals. This article has important theoretical and practical significance for future experts and scholars in related fields to study one or more kinds M\&A behavior.
\end{abstract}

Keywords-Mergers and Acquisitions; M\&A motivation; M\&A behavior

\section{INTRODUCTION}

All along, Western economics has devoted itself to studying the role of human behavior in economic activities, McGregor proposed the concept of "economic man" hypothesis Simon put forward the concept of "limited rationality" on the basis of complete rationality. Thaler integrated "limited" thinking into human behavior analysis, opening up new areas of behavioral economics, and making humanity more economical. In 2017, the global M\&A market announced a transaction volume of up to 3.7 trillion U.S. dollars, the fifth highest level in history. At the same time, some details are worth noting: the total transaction amount decreased by $4 \%$ year-on-year, the ultra-large-scale volume of more than US\$10 billion decreased by 5\% year-on-year, the total amount of transactions withdrawn was up to US\$685 billion, and strategic acquisition accounted for 78\% [1] (Zhao, 2018). It can be seen that with the rapid development of the global economy and the intensified competition in recent years, the company's M\&A have ushered in an unprecedented new situation both in terms of scale and transaction volume. The company is composed of shareholders and employees, similar to the human behavior of researchers in behavioral economics. The company's M\&A behavior is the company's collective choice under different motives. Most of the acquirers wanting to carry out M\&A have a certain purpose, which has a certain motivation and behavior characteristics.

We mainly use literature collection methods to study, using news media (Baidu News and Tencent News), search engines (Google search and Baidu search), libraries (National Library and Beijing Jiaotong University Library) and domestic and international literature search institutions (CNKI and web of science) collect information about mergers and acquisitions. We find that most M\&A studies cannot be separated from the economic consequences caused by M\&A motives. Then the link between this motive and the economic consequences is reflected in a certain behavior from the side. Because the motives lead to more closely linked behavior, we find that it is difficult to completely distinguish between motivation and behavior when collecting literature and reading. One motivation may lead to multiple behaviors, and one behavior may be due to multiple motivations. In addition, not every M\&A behavior study has a more complete framework of motivation, behavior, and economic consequences. Some M\&A behaviors involve less research on their motivation or economic consequences and cannot form separate review chapters. Therefore, we no longer summarize the motives and economic consequences of each M\&A behavior separately, embody the motives and economic consequences in behavioral research, and unify them into behavioral research paradigms. According to the massive literature, a total of five kinds of the same or similar M\&A behaviors were analyzed, including: related $\mathrm{M} \& \mathrm{~A}, \mathrm{M} \& \mathrm{~A}$ premium, excessive $\mathrm{M} \& \mathrm{~A}, \mathrm{M} \& \mathrm{~A}$ geographical selection and M\&A peer behavior. Below we analyze one by one as follows.

\section{Classification OF M\&A Behavior}

\section{A. Related M\&A}

Relevant M\&A are an important form of related-party transactions, which are accomplished through the acquisition, transfer, and replacement of equity between parent companies. In response to this problem, scholars mainly conduct research on the causes of related M\&A, related M\&A and company operating performance, related $\mathrm{M} \& \mathrm{~A}$ and corporate value, "Tunneling" and "propping" in related M\&A. In addition, Chinese scholars have conducted in-depth studies on related M\&A combined with China's national conditions and special systems.

1) Causes of related M\&A: Jian and Wong (2003) through the classification study believe that, the motives of the controlling shareholders of listed companies to perform related M\&A stem from profit transfer and "protection of shells". Deng et al. (2011) believe that the equity structure of Chinese listed companies does not significantly affect the occurrence of related M\&A, and the joint-stock reform model is the root cause of the related M\&A [2].

2) Related M\&A and company operating performance: Some scholars have found that related M\&A are beneficial to 
improving corporate performance. Pan and Chen (2005) selected the related M\&A sample group and the non- related M\&A control sample group, found that the related M\&A sample group had higher M\&A performance than the nonrelated M\&A control sample group. Furthermore, scholars have found that both short-term and long-term related M\&A can significantly improve corporate performance ( $\mathrm{Li}$ et al., 2013). Some scholars have also found that related M\&A are not conducive to improving corporate performance. Cheung et al. (2007) focused on the related M\&A of mainland companies listed on Hong Kong stocks as a research object and found that the excess returns of the acquirer on the M\&A announcement date and subsequent 12 months were significantly lower than other companies in the same period. There are also scholars believe that it is impossible to generalize whether related M\&A are beneficial to improve enterprise performance. Deng et al. (2011) found that in companies with a turnaround or refinancing motive, the performance of related $M \& A$ were higher than that of non- related M\&A performance [2].

3) Related M\&A and company value: Claessens and Fan (2003) have studied that the group companies transfer their profits internally in the form of related M\&A, and that the motives are mostly for the remedy of operational difficulties. This can easily cause the group companies to lose their profits. Deng et al. (2011) found that non-related M\&A can bring wealth effects to shareholders, while related M\&A cannot create wealth for shareholders [2].

4) “Tunneling” and "propping” in related M\&A: Johnson and Boone (2000) first proposed the "Tunneling" theory, which is used to describe the phenomenon that controlling shareholders transfer their corporate assets and profits for their own interests through related M\&A, which indirectly harms the interests of minority shareholders [3]. Friedman et al. (2003) first proposed the "propping" theory, which is exactly the opposite of the "Tunneling" theory. It is used to describe the behavior of controlling shareholders that the company can bring more profits to shareholders (including small and medium shareholders) and support the company.

Some scholars have researched related M\&A based on the behavior of "Tunneling". Bulletin et al. (2002) took Indian companies as the research object. After analyzing the corporate resources plundered by the controlling shareholders of the company, it was found that Most Indian companies are "Tunneling" based on related M\&A. Chinese scholars have specialized in the research of related M\&A between listed companies and major shareholders, and have obtained major shareholders' "Tunneling" motivation for launching M\&A (Li et al., 2009). Some scholars have researched related M\&A based on the behavior of "propping". Chen and Jia (2013) in the study found that when the equity financing preference of related M\&A motivation before and after a year of for-profit financial indicators did not meet the requirements of a rights issue after the related M\&A performance of listed companies have obvious rise, there is "propping" behavior. There are also scholars who study the "Tunneling" and "propping" behavior in related M\&A. Huang and Shen (2006) believe that the major shareholder has "Tunneling" obvious motivation in the related M\&A of listed companies with good performance, while the major shareholder has "propping" motivation in the related M\&A of companies with average or bad performance [4].

5) Summary: Comprehensive literature finds that scholars try to find the motivation and reasons for the associated M\&A through various channels. We also studied the economic consequences of associated M\&A, mainly related to the company's operating performance and company value, but the conclusions are not consistent, and further research is needed for this. Due to the special nature of the related M\&A, a large number of studies have focused on the "Tunneling" and "propping" behavior of the controlling shareholders in the related M\&A. However, from the current perspective, it is still the study of the majority of "Tunneling" behavior of controlling shareholders. In fact, the controlling shareholder's "propping" behavior for listed company is also common. In order to fully understand the motives of the controlling shareholders of the listed companies in the related M\&A, the concurrent research both on the "Tunneling" and "propping" behavior of the controlling shareholders is one direction in the future.

\section{B. M\&A Premium}

There has been a lot of literature research on M\&A premiums, and scholars have analyzed it from various aspects. Summarized mainly include: the causes of the M\&A premium, the influencing factors of the M\&A premium, the valuation model of the M\&A premium, the economic consequences of the M\&A premium, the impact on the performance of $M \& A$, and the measurement method selection of the M\&A premium.

1) Reasons for M\&A premium: Scholars mainly study the causes of M\&A premiums from the perspective of synergy theory, principal-agent theory, and overconfidence theory. First of all, the theory of synergy refers to the fact that the overall value of an enterprise after M\&A will surpass the sum of the value of each enterprise before the M\&A occurs, resulting in the effect of " $1+1>2$ ". Bradley (1980) after research found that in order to promote the completion of M\&A, acquirer will be forced to accept a higher M\&A price, and then the resulting premium will be relatively high. Yuan and Zou (2011) studied the industry and found that the same industry would generate a higher M\&A premium. Then, some scholars explained the premium of M\&A by entrusting agency theory. The principal-agent theory believes that in order to consolidate its position in the company, increasing market share through higher capital acquisitions, which increases the market position of the company and creates a merger premium [5] (Jensen, 1986). Scholars have also empirically tested that M\&A premiums may be affected by the M\&A agency issues (Lei, 2006). Again, the over-confidence theory of managers is used to explain M\&A premiums. This theory believes that M\&A activity is the acquisition of the CEO, because transitional confidence, it does not properly assess the gains that can be obtained, and causes the purchaser to pay a far higher price than the target's real value, resulting in a higher premium (Hao et al., 2005). 
2) Influencing factors of $M \& A$ premium: Scholars mainly explore the market environment and transaction characteristics. First of all, for the market environment, the macroenvironment and industry environment in which M\&A take place, including political, economic, and cultural factors, will affect the premium of M\&A. Second, for transaction characteristics, such as M\&A valuation, investment in intermediary expenses, M\&A payment methods and the existence of competitors will affect the premium of M\&A. If the company's market value is seriously underestimated, then a relatively high M\&A premium will be paid in the M\&A valuation, bring the value of the company to a reasonable state (Shleifer and Vishny, 2003). Chahine (2009) finds that there is a correlation between agency costs and M\&A premiums. For the acquirer, there is a significant negative correlation, and for the acquiree, there is a significant positive correlation. Chen and Cheng (2012) believe that if the acquirer has a competitor, it may pay a higher M\&A premium to increase the probability of a successful acquisition. Ge et al. (2014) showed that the share premium paid for M\&A is higher than cash payment [6].

3) M\&A premium valuation model: Research on $\mathrm{M} \& \mathrm{~A}$ pricing has been studied earlier by scholars. Lin (2005) focuses on the real options pricing model in the field of M\&A pricing. Bao (2006) believes that the premium of equity acquisition can use four methods: option pricing method, value added sharing method, comparative analysis method and empirical method. Zhao and Ren (2008) discussed the incremental cash flow method to measure M\&A premiums. Guo and Xiang (2009) constructed an objective and practical target value evaluation model for companies to provide guidance for M\&A practice. Cheng et al. (2013) addressed the rationality of the valuation method of M\&A reorganization for the valuation of the income method, and elaborated on the work of the enterprise value evaluation and transaction pricing in two different ways [7]. There are two main indicators of M\&A premiums. One is based on market prices. The indicator uses the stock market price to measure the value of the target company. The formula is: M\&A premium $=($ price per share per stock market price)/per stock price (Haunschild, 1994). The other is based on the net book value of assets, and the formula is: M\&A premium = (trading price-net assets of the target company)/net assets of the target company [8] (Xie and Zhang, 2013; Chen and Lu, 2013).

4) Economic consequences of M\&A premiums: For the economic consequences of the acquiree's shareholders, scholars generally believe that the M\&A premium can bring benefits to the acquiree's shareholders, and the company pays a higher merger premium, making the acquiree's shareholders gain additional income. The economic consequences for the acquirer are more complex, and only the value derived from the synergy effect of M\&A is greater than the premium of the M\&A. Some scholars have found that M\&A premiums are conducive to improving M\&A performance [9] (Walkling and Edmister, 1985; Li et al., 2004; Cheng, 2009). Some scholars believe that paying an excessively high M\&A premium will erode the company's future operating performance (Sirower, 1997; Huang and Gan, 2009; Yan, 2012). Some scholars have also given a reasonable range of M\&A premium payments. Bao (2006) pointed out that the successful M\&A premium interval is $10 \%-20 \%$; when the M\&A premium exceed $50 \%$, the acquirer is prone to losses and even goes bankrupt.

5) Summary: As can be seen from the literature, scholars have a general understanding of the factors that influence the merger premium from the perspective of the acquirer. Taking the motivation of M\&A behavior as the starting point, it is of great significance to study the M\&A premium from the perspective of the acquirer. However, we have found that former scholars have overlooked an important factor that is another party to the M\&A. We believe that the M\&A process is the result of mutual game between M\&A parties. The acquirer wants to obtain control of the acquired party at a lower price, and the same target business owner also wants to obtain better returns. Due to the information asymmetry between the acquiring party and the acquired party, the M\&A pricing process is a game between the acquiring party and the acquired party. Therefore, it is necessary to further study the M\&A premium from both theoretical and practical perspectives.

\section{Excessive $M \& A$}

At present, there are not many studies on excessive M\&A. M\&A is a major form of investment. Previous scholars mainly focus on over-investment perspectives from the perspective of management power under the principal-agent theory, management power under the theory of business behavior, management power under the perspective of compensation, and management power under the perspective of asymmetric information in four areas to research.

1) Management power under the principal-agent theory: Similar to the principal-agent theory of explaining the premium of M\&A, managers usually make a series of investments for their own benefit in order to achieve a beautiful performance. Because shareholders cannot participate in the company's daily business activities at any time, especially small and medium-sized stocks, it is impossible to supervise managers' investment decisions, resulting in excessive investment (Berle et al., 1932). Some scholars also found that the higher the degree of ownership concentration of the company, the closer the connection between the major shareholders and the senior management, resulting in the combination of the two companies through excessive investment in the transfer of corporate profits to jointly harm the interests of small and medium shareholders. This is another manifestation of the principal-agent problem (Shleifer and Vishny, 1997; LoPorta et al., 1999; Claessens et al., 2002).

2) Management power under the theory of business behavior: Some scholars believe that managers sometimes make good decisions when they make decisions, but they cannot maintain absolute rationality. The complexity of the decision-making environment and future uncertainties lead managers to make irrational decisions (Kahneman et al., 1986). When managers are in a larger internal competition 
environment, they are particularly concerned with the reelection of the management team. Managers are often forced to consider their own conditions and increase their investment to increase their performance in order to achieve their own future development in the company [10] (Murphy, 1985, Shleifer and Vishny, 1997). Some scholars believe that diversification of investment can increase the managerial ability of managers and thus increase social prestige. Therefore, management is loyal to diversified investments (Gibbons and Murphy, 1992).

3) Management power under the perspective of compensation: Generally speaking, the larger the company is, the more complex the management's handling of matters and the higher the management's salary. Therefore, management overinvests in order to obtain higher compensation, especially when management believes that the payoff is not proportional, this phenomenon is more prominent (Wei, 2000). Some scholars have also found that in China's state-owned enterprises, the greater the power of management and the higher the level of compensation, the greater the power of management of large-scale enterprises than that of small enterprises. Therefore, management power is also one of the main factors leading to excessive investment (Dai et al., 2011).

4) Management power under the perspective of accounting information quality: The quality of accounting information is affected by many factors, such as the perfection of accounting standards, government supervision, the internal control system of the company, and the quality of the accounting personnel. It is an important part of the company's financial work to ensure the quality of accounting information. Some scholars have found that the high quality of accounting information is conducive to the suppression of excessive investment ( $\mathrm{Li}, 2009)$. Some scholars have also linked the quality of accounting information with the power of management, and believe that higher management authority can interfere with the quality of accounting information, thus affecting the over-investment of enterprises (Yuan et al., 2010).

5) Summary: Some scholars believe that M\&A are one of the most important forms of investment, and M\&A are equated with investment, and excessive $M \& A$ is equivalent to over-investment. We believe that excessive M\&A and overinvestment are two completely different concepts that cannot be confused. The former emphasizes all the investment of the company, while the latter emphasizes the consideration paid by the M\&A. M\&A is only part of the investment. It is unscientific and unfounded to use over-investment instead of excessive M\&A. The measurement of excessive M\&A is a difficult point in empirical research. As for how to measure the degree of excessive M\&A, there has been no theoretical explanation, and there is no direct mathematical model available for reference. According to the internal and external factors of the scale of M\&A, expect that the scale of M\&A will have a higher degree of scientificity, and it is a reasonable M\&A scale. The actual M\&A scale is the amount paid by the buyer in the M\&A case. The difference between the actual
M\&A scale and the expected M\&A scale is more than 0 , which is excessive M\&A. How to determine the scale of rational M\&A is the focus and difficulty of future research.

\section{M\&A Geographical Selection}

The research on the regional selection literature of M\&A is relatively abundant, mainly including: the motivations of crossregional (national) $\mathrm{M} \& \mathrm{~A}$, the influencing factors of crossregional (national) $\mathrm{M} \& \mathrm{~A}$, and the performance of crossregional (national) $M \& A$.

1) Motivation for cross-regional (national) M\&A: For cross-regional M\&A, the economic development, policy formulation, and cultural conventions in different regions of the same country are all different. This has led companies to adjust their business strategies according to different regional environments. Some scholars have pointed out that crossregional M\&A are also an effective way to ease regional heterogeneity. Not only that, but also to achieve coordinated development and further increase the overall value of the company (Fang, 2009; Tang and Chen, 2010; Yuan, 2011; Hu, et al., 2012). Wang and Miao (2015) believe that the causes of cross-regional M\&A of enterprises mainly include two aspects: one is the cost driver and the other is the growth driver. For cross-border M\&A, Linna (2007) believes that seeking labor, obtaining technical support, increasing brand value, and extending the value chain of integration are the main reasons for companies to conduct cross-border M\&A. Chen (2009) conducted research on Chinese companies' overseas M\&A. He believed that the rapid development of the global economy, changes in China's foreign policy, changes in the strategic layout of the company's own investment, and the political, economic and cultural environment of the country where the acquirer is located are important influencing factors.

2) The influencing factors of cross-regional (national) M\&A: Through literature reading, the factors affecting crossborder M\&A generally proceed from the perspective of crossborder M\&A motives. For cross-regional M\&A, the main factors we have summed up are government intervention and plunder.

First, scholars believe that cross-regional M\&A involve the absorption of local companies from the perspective of the acquiree's government. The government is usually unwilling to be acquired because of its own control the company, so it will set relevant policies to hinder the smooth progress of the acquisition (Luo, 2004). Fang (2008) conducted a study based on the classification of state-owned enterprises in China, and concluded that central state-owned enterprises can break through local government interventions to implement crossregional M\&A, while local state-owned enterprises cannot. Pan and $\mathrm{Yu}$ (2011) have even discovered that local state-owned enterprises are more difficult to implement cross-regional M\&A than private enterprises [11]. However, some scholars have also found that sometimes local state-owned enterprises actively engage in cross-regional M\&A in order to get rid of local government plunder [12] (Yao et al., 2014). There are also scholars studying political connections and cross-regional M\&A. Jiang et al. (2013) found that the depth of political 
connections is more significant than the width of political connections in the cross-regional M\&A of private enterprises.

3) The performance of cross-regional (national) $M \& A$ : In terms of the performance of cross-border M\&A, some scholars have studied and found that the performance of cross-border M\&A improved. Dodde and Ruback (1977) first started the study of cross-border M\&A performance. Hu and Han (2016) used market performance research methods to study the shortterm wealth effects of the acquirer and its influencing factors, indicating that the acquirer's shareholders have achieved a significant wealth effect. Some scholars have found that after the cross-border M\&A performance decreased. Feng et al. (2001) found that the company's performance after crossborder M\&A showed a trend of going public in a short period of time, but then it fell. Similarly, Chen and Mao (2011) found through empirical analysis that the company's performance in the year of M\&A increased significantly, but then began to gradually decline, M\&A did not substantially improve the company's performance. Some scholars also found that corporate performance after cross-border M\&A has not changed. He and $\mathrm{Lu}$ (2010) used event research methods to conduct research on manufacturing companies that had transnational M\&A. Research shows that the performance of manufacturing companies after M\&A has not changed significantly.

In cross-regional M\&A performance, scholars first studied the cross-regional M\&A performance of companies of different natures. Pan and $\mathrm{Yu}(2009,2010)$ proved that private listed companies have a significant effect on cross-regional M\&A over local state-owned enterprises, and that cross-regional M\&A perform better. The research of Zhou and Song (2013) shows that central state-owned enterprises have higher performance in cross-regional M\&A than local state-owned enterprises. In addition, some scholars also analyze the influence of cross-regional M\&A performance on the aspects of institutional theory and institutional distance. Le and Lan (2012) believe that the external legitimacy under the institutional theory has an important impact on cross-regional M\&A. If there are certain external legitimacy barriers to crossregional M\&A, M\&A performance will be significantly reduced. Song and Zhong (2013) found that the institutional distance between the warfare alliances' regions and the complementary resources of the alliance's resources, the performance of strategic alliances have an inverted U-shaped relationship [13].

4) Summary: At present, the motivations and influencing factors for cross-region (national) M\&A are already very rich, but the conclusions about cross-regional (national) M\&A performance research are different. It may be due to the huge difference in sample selection that leads to no unanimous conclusion. There is also the heterogeneity of the environment in which the sample is located, including macro-political, economic, cultural and medium-term industries, and the industrial environment. This will affect the effect of M\&A. We think that although cross-region (national) M\&A are heterogeneous in nature, but the future research on crossregion (national) M\&A can still focus on the characteristics of environmental heterogeneity, classification research the same industry as the unit, and the sample is limited as much as possible to the conditions of the macro-environments in the same period, and then cross-regional (national) M\&A performance is studied to obtain a more persuasive in conclusion.

\section{E. M\&A Peer Behavior}

The scholars of literature on M\&A peer behavior mainly study M\&A peer effects. M\&A peer effects are the manifestations of certain M\&A peer behavior. In the economic field, individual companies of the same type of industry reduce the uncertainty of decision making by imitating learning from each other, resulting in a certain similarity in decision-making, which is called peer effect. If this kind of decision-making is a M\&A decision, it is the M\&A peer effect. The literature about M\&A peer effects mainly studies the inter-organizational imitation research of $M \& A$ decision-making and the forming mechanism of M\&A decision-making peer effect.

1) The inter-organizational imitation research of $M \& A$ decision-making: Haunschild (1993, 1994) studied companies with chained directorships and found that the company's M\&A decisions were imitated by the association of directors. In addition, it was further found that the imitation behavior included M\&A premium decision. Chen et al. (2013) based on this have further expanded and studied the regulatory effects of "Imitating the Three Laws" on M\&A premium decisions. In addition, the imitative behavior between organizations is not only reflected in M\&A decision-making, but also reflected in some other business aspects of the company, such as the R\&D investment of technology and the construction of organizations. Inter-organizational imitation behavior is a direct factor that contributes to the formation of peer effects. Therefore, these documents also provide a theoretical basis for M\&A peer effects.

2) $M \& A$ decision-making group effect formation mechanism: There are few literatures on the formation mechanism of cohort effects. The existing literature scholars mainly study the peer effects based on information acquisition imitation. Haunschild's (1993) research shows that companies are very concerned about M\&A information of related companies. When firms are uncertain about M\&A valuations, they often refer to M\&A information of related companies, which can make better decisions. Westphal et al. (2001) also found that most acquisitions of M\&A knowledge come from related companies. Chen et al. (2013) aiming at M\&A premium decision, found that companies would obtain M\&A premium decision information from chained directors' affiliates as a guide. Wan and Zheng (2014) found that the higher the degree of centrality of the listed company's independent directors, the more frequent the M\&A [14]. From the position of the director network center, M\&A information and $M \& A$ opportunities can be quickly obtained to explain this problem. We believe that due to the high similarities in the internal environment of the industry, information on M\&A is particularly important within the industry. M\&A information will be used to provide reference for M\&A in the 
same industry, which in turn will promote the occurrence of $M \& A$ in the same industry, thus showing the peer effects.

3) Summary: According to the existing literature, first of all, there have the peer effects in the predecessors' research on M\&A behavior. However, at present, whether such peer behavior will affect the performance of M\&A and causing the failure of M\&A is mostly a normative analysis. There is no demonstration, and further empirical tests are needed in the future. Second, there are also some differences in the content of research between the organization's imitation research and the peer effects: First of all, although the former studies the relationship between organizations, it generally treats organizations as individuals and actually studies the relationships between individuals. The latter focuses on the relationship between individuals and organizations and studies the impact of organizations on individuals. Therefore, the differences between the inter-organizational mimicry and the peer effects can be further explored in the future.

\section{CONCLUSION AND SugGestion}

\section{A. Conclusion}

According to the behavioral economic analysis framework, from motivation to behavior, and then from behavior to economic consequences, the economic consequences in this paper are mostly performance studies. If M\&A performance is a variable that is relatively easy to quantify and monitor, M\&A behavior involves a wide range of content. The classification of M\&A has not been specifically studied. We have summarized and analyzed the same or similar M\&A behavior from a vast amount of literature, including: related M\&A, M\&A premium, excessive M\&A, M\&A geographical selection and M\&A peer behavior in five sub-categories. A summary of existing research findings, deficiencies, and future research directions for each M\&A behavior, and no repeated discussion will be made here.

\section{B. Suggestion}

The categorization of M\&A behavior is far more than a study of M\&A itself. For example: Under the background of the mixed ownership reform of state-owned enterprises in China, institutional investors as professional investment institutions have strong capabilities to identify M\&A behavior that may harm the value of the company. China's state-owned enterprises are generally more related, and state-owned enterprises may themselves choose state-owned enterprises as targets for M\&A. Therefore, from the perspective of improving corporate governance, institutional investors have the incentive to reduce the occurrence of potential value-damaged M\&A such as the M\&A of state-owned enterprises and other affiliated companies. In addition, the majority of existing studies believe that institutional investors are homogeneous and based on the degree of "shareholder activism", it can be extended to examine the heterogeneity of institutional investors and examine the impact of different types of institutional investors on the M\&A behavior of state-owned enterprises. The conclusion on the differential effectiveness of institutional investors' heterogeneity provides an important reference for the appropriate introduction of different types of institutional investors in the mixed ownership reform of Chinese stateowned enterprises while studying the M\&A behavior of stateowned enterprises. It has important theoretical and practical significance for the reform of mixed ownership of state-owned enterprises. Therefore, the classification of M\&A behavior also provides a broad space for future research on the relationship between M\&A behavior and other things.

\section{ACKNOWLEDGMENT}

This article is one of the phased achievements of the key project of the National Social Science Fund "Research on the Effectiveness of Equity Restructuring of Competitive StateOwned Enterprises Based on the Motivation of Mixed Ownership Reform" (17BGL074) and the Humanities and Social Science Fund Project of Ministry of Education "Merger of Institutional Investors, M\&A of State-owned Enterprises and M\&A Performance" (16YJA630079). Thanks for the above two funds support.

\section{REFERENCES}

[1] Y. Zhao, JPMorgan chase looks at the global M\&A market in 2018: technology drives global change, China reachs overseas journeys [EB/OL].https://wallstreetcn.com/articles/373226.

[2] J.P. Deng, Y. Zeng, and J. He, "Associated M\&A and reorganization: roots and consequences," Chinese Journal of Management, vol. 8, pp. 1238-1246, August 2011.

[3] S. Johnson, P. Boone, A. Breach, and E. Friedman, "Corporate governance in the Asian financial crisis," Journal of Financial Economics, vol. 58, pp. 141-186, January 2000.

[4] X.L. Huang and W.T. Shen, "Propping or pulling out--empirical analysis from related acquisitions of Chinese Listed Companies," Economic Management Journal, pp. 57-64, Decembery 2006.

[5] M.C. Jensen, "Agency cost of free cash flow, corporate finance," American Economic Review, vol. 76, pp. 323-329, February 1986.

[6] W.J. Ge, Q.S. Zhang, and Z.Q. Zhang, "Research on payment methods, financing constraints and M\&A premiums," Securities Market Report, pp. 40-47, January 2014.

[7] F.C. Cheng, X. Liu, and X. Wen, "The study of the relationship between the listed companies' underlying asset appraisal and the transaction pricing," Accounting Research, pp. 40-46, August 2013.

[8] S.H. Chen and C.C. Lu, "Executive coupling between firms and M\&A premium decision: an empirical study based on the theory of interorganizational imitation," Management World, vol. 5, pp. 144-156, May 2013.

[9] R.A. Walkling and R.O. Edmister, "Determinants of tender offer premiums," Financial Analysts Journal, vol. 41, pp. 27-37, January 1985.

[10] K.J. Murphy, "Corporate performance and managerial remuneration: an empirical analysis," Journal of Accounting \& Economics, vol. 7, pp. 1142, January 1985.

[11] H.B. Pan and M.G. Yu, "Helping hand, grabbing hand and interprovince mergers," Economic Research Journal, pp. 108-120, September 2011.

[12] Y.L. Yao, J.S. Liu, and D.Y. Liu, "Factor market development difference, company properties and M\&A performance," Nankai Business Review, vol. 17, pp. 102-111, May 2014.

[13] T.B. Song and B. Zhong, "A study on the relationship between institutional distance and cross-regional strategic alliance performance," Science and Management of Science and Technology, vol. 34, pp. 42-50, March 2013.

[14] L.Y. Wan and X.L. Zheng, "Structural hole of board networks and M\&A,” Accounting Research, pp. 67-72, May 2014. 